\title{
Ocorrência de Actinomicetos com atividade proteolitica, em um solo cultivado
}

\author{
S. Joly \\ Instituto Zimotécnico \\ Escola Superior de Agricultura «Luiz de Queiroz»
}

(*) Recebido para publicação em 5/7/60. 


\section{1. - INTRODUÇÃO}

Os Actinomicetos são organismos de amplo habitat natural, sendo portanto o solo um meio ambiente que faculta a êsses sêres condições completas de desenvolvimento.

Freqüentes habitantes do solo como são, necessàriamente participam das sinteses quimicas, das interações antagônicas e dos demais processos bio-pedológicos que se desenvolvem nesse ambiente natural.

Fazendo parte de sell equipamento enzimático figura a protease, responsável pela demolição do substrato proteíco, através das formas mais simples que são os aminoácidos e depois amônia.

A habilidade proteolitica dos Actinomicetos é manifesta tambèm contra bactérias fitopatogênicas; em ambos os casos concorre para a realização do grande ciclo do nitrogênio na natureza.

Os primeiros informes que registram a existência dos Actinomicetos como integrantes da flora terricola, datam de 1888, segundo nos conta WAKSMAN (1950), poнcos anos após sua primeira descrição que se realizou cm 1875; em 1900, BEIJERINCK constatou que êsses organismos habitam não só o solo, mas também o sub-solo.

Nessa mesma época, em 1900, NADSON (segundo WAKS. MAN, 1950) registrou o função dêsses sêres nas modificações geológicas, pois, do lodo de lago salyado pòde isolar algumas cepas com capacidade de decompor proteinas, produzir amônia e $\mathrm{H}_{2} \mathrm{~S}$, assim como precipitar $\mathrm{CaCO}_{3}$.

Vivem em solos não cultivados ou cultivados (WAKSMAN, 1916), com largo limite de variação de $\mathrm{pH}$, solos férteis ou não, ocorrendo em tôdas as regiōes do gloho, representados por muitos gêneros e espécies (WAKSMAN, 1918).

\section{2. - MATERIAL E MÉTODOS}

Isolamos 340 cepas de Actinomicetos de um solo Latosol vermelho amarelo, cultivado com cafeeiro, de acidez média, com $\mathrm{pH}$ $5,5-5,8$; o teor de umidade atingiu o mínimo de 4,5\% e o máximo de $62 \%$ respectivamente nos meses com menor e maior precipitação pluviométrica. $\mathrm{O}$ valor em matẻria orgânica foi em média de 4,099.

A amostragem se fêz pelo espaço de 12 meses, para atingir as 4 estações anuais, em 1958.

As amostras de solo foram coletadas mensalnente, homogenisando-se passando-se em tamis de malha $1,651 \mathrm{~mm}$. 
Feita a diluição em água estéril, semeamos em méeio de amido agar (BALDACCl 1953), cuja fórmula é a seguinte:

Sol. I

Meio de amido agar

Amido solúvel $\ldots \ldots \ldots \ldots \ldots \ldots \ldots \ldots \ldots, 10,0 \mathrm{~g}$ $\mathrm{H}_{2} \mathrm{O} \ldots \ldots \ldots \ldots \ldots \ldots \ldots \ldots \ldots, 500 \mathrm{ml}$

Sol. II

$\mathrm{K}_{2} \mathrm{HPO}_{4} \ldots \ldots \ldots \ldots \ldots \ldots \ldots \ldots \ldots \ldots \ldots, 1,0$

$\mathrm{MgSO}_{4} .7 \mathrm{H}_{2} \mathrm{O} \quad \ldots \ldots \ldots \ldots \ldots \ldots \ldots \ldots, \quad 1,0$

Misturam-se as duas saluções (I e II) e junta-se,

$\mathrm{NaCI} \ldots \ldots \ldots \ldots \ldots \ldots \ldots \ldots \ldots \ldots, 1,0$

$\left(\mathrm{NH}_{4}\right)_{2} \mathrm{SO}_{4} \ldots \ldots \ldots \ldots \ldots \ldots \ldots \ldots \ldots, 2,0$

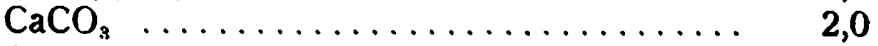

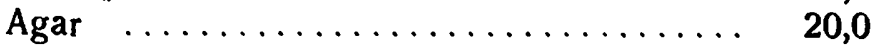

Incubaram-se as caixas assim semeadas em estufa a $32^{\circ} \mathrm{C}$ por 3-4 dias. Quando se desenvolveram as colônias elàs foram purificadas no mesmo meio agarisado por 2-3 passagens sucesisvas até que se apresentassem puras.

A prova da presença de enzima proteolítica foi feita em meio de gelatina a $10 \%$ em solução aquosa. As culturas foram incubadas em estufa, sendo feita a leitura com vários dias de desenvolvimento, conforme Quadro I, sendo feita a última leitura ao $30^{\circ}$ dia.

As cepas de n. ${ }^{4} 1$ a 86 foram isoladas nos meses de Janeiro a Março: de 87 a 165, nos meses de Abril a Junho: de 166 a 225, nos meses de Julho a Setembro: de 226 a 340, nos meses de Outubro a Dezembro, correspondentes ao verão, outono, inverno e primavera.

Foram eliminadas as cenas de ns. $48,59,108,116,131,143,144$, $158,187,310,313,322$ e 333 , por terem contraído contaminação no decorrer do trabalho.

\section{3 - RESULTADOS}

O resultado da atividade proteolítica aparece nos quadros I - IV e nos gráficos l - IV. 
Q U A D R O I

ATIVIDADE PROTEOLITICA

\begin{tabular}{|c|c|c|c|}
\hline $\begin{array}{l}\text { No da } \\
\text { cepa }\end{array}$ & $\begin{array}{l}\text { No de } \\
\text { dias }\end{array}$ & Desenvolvimento & Pigmento solúvel \\
\hline $\begin{array}{l}1 \\
2 \\
3 \\
4 \\
5 \\
6 \\
7 \\
8 \\
9 \\
10 \\
11 \\
12 \\
13 \\
14 \\
15 \\
16 \\
17 \\
18 \\
19 \\
20 \\
21 \\
22 \\
23 \\
24 \\
25 \\
26 \\
27 \\
23 \\
29 \\
30 \\
31 \\
32 \\
33 \\
34 \\
35 \\
36 \\
37 \\
38 \\
39 \\
40 \\
41 \\
42 \\
43 \\
44 \\
45 \\
46 \\
47 \\
49\end{array}$ & $\begin{array}{l}18 \\
21 \\
18 \\
(-) \\
18 \\
19 \\
18 \\
18 \\
19 \\
18 \\
21 \\
18 \\
18 \\
21 \\
18 \\
18 \\
18 \\
21 \\
(-) \\
18 \\
18 \\
21 \\
19 \\
19 \\
18 \\
21 \\
21 \\
18 \\
18 \\
18 \\
21 \\
19 \\
15 \\
19 \\
19 \\
19 \\
21 \\
18 \\
18 \\
18 \\
19 \\
19 \\
18 \\
18 \\
19 \\
18 \\
21 \\
21\end{array}$ & 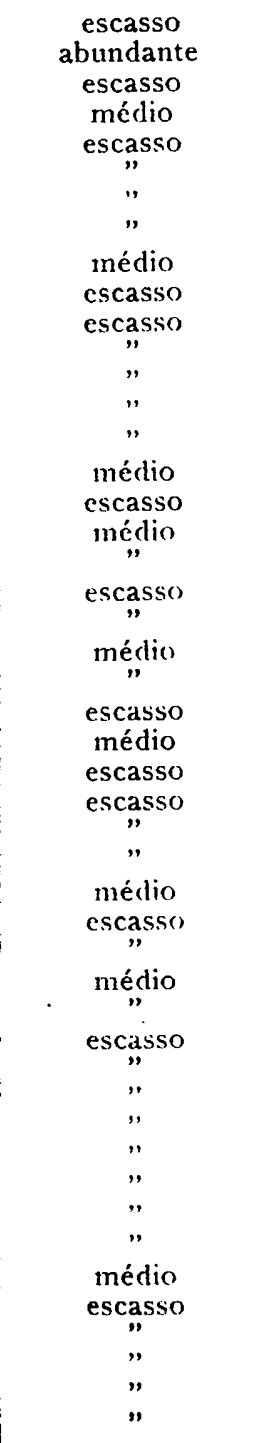 & $\begin{array}{l}\text { amarelo } \\
\text { csverdeado } \\
\text { amarelo } \\
\text { amarelo dourado } \\
\text { amarelo dourado } \\
\text { amarelo } \\
\text { amarelo forte } \\
\text { amarelo } \\
\text { creme claro } \\
\text { amarelo forte } \\
\text { amarelo } \\
\text { amarelo forte } \\
\text { creme claro } \\
\text { amarclo } \\
\text { amarelo } \\
\text { amarelo claro } \\
\text { aniarelo } \\
\text { verde claro } \\
\text { amarelo } \\
\text { verde } \\
\text { amarelo dourado } \\
\text { amarelo } \\
\text { amartlo } \\
\text { amarelo } \\
\text { amarelo avermelhado } \\
\text { castanho vinhoso } \\
\text { amarelo } \\
\text { côr de vinho } \\
\text { amarelo } \\
\text { amarelo dourado } \\
\text { amarelo dourado } \\
\text { amarelo } \\
\text { amarelo } \\
\text { amarelo } \\
\text { creme claro } \\
\text { amarelo } \\
\text { amarelo forte } \\
\text { amarelo } \\
\text { amarelo }\end{array}$ \\
\hline
\end{tabular}




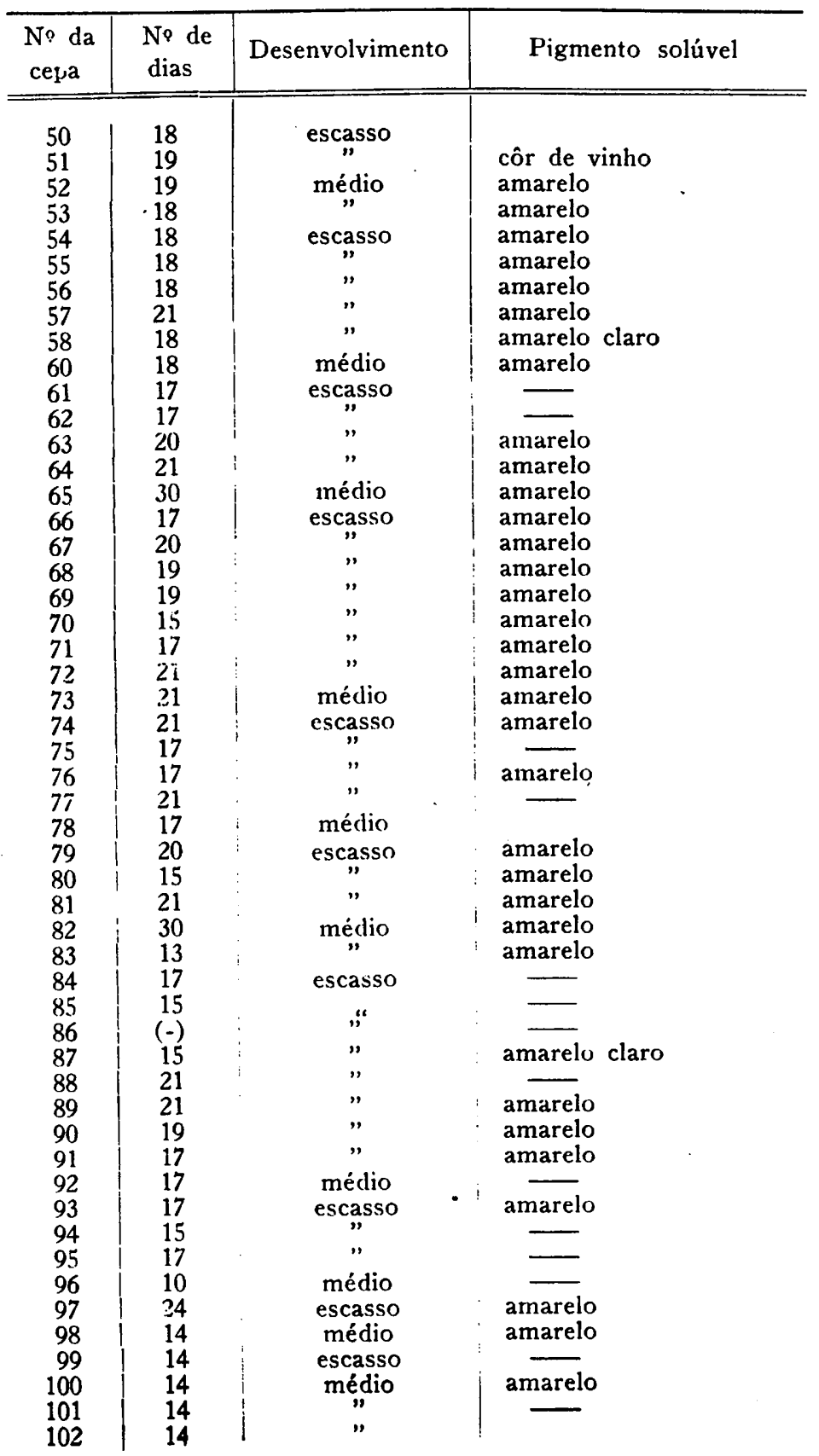




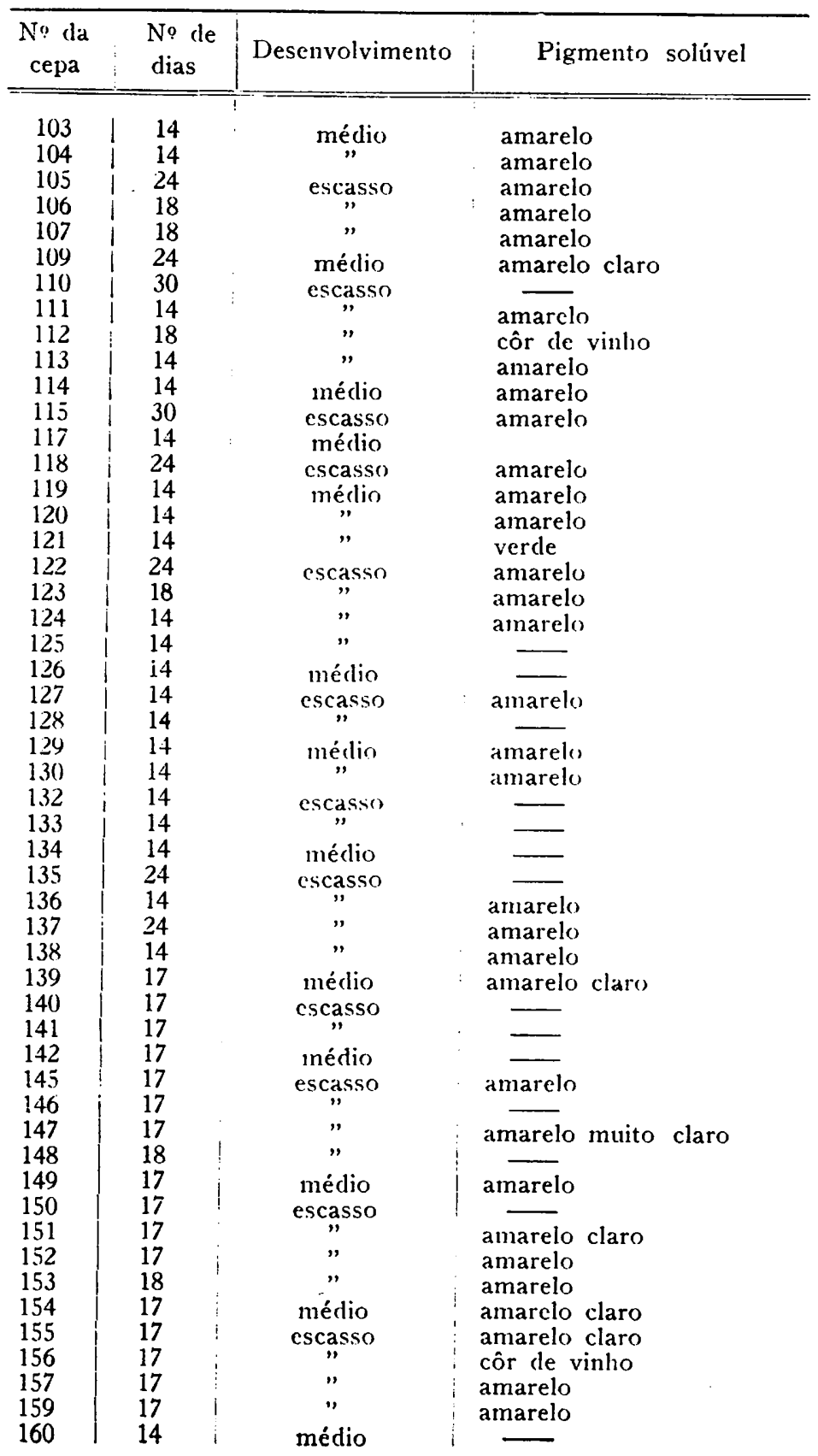




\begin{tabular}{|c|c|c|c|c|}
\hline $\begin{array}{c}\text { No cla } \\
\text { cepa }\end{array}$ & $\begin{array}{l}\text { No de } \\
\text { dias }\end{array}$ & Desenvolvimento & $!$ & Pigmento solúvel \\
\hline 161 & 17 & escasso & . & amarelo \\
\hline 162 & 24 & " & & anıarelo \\
\hline 163 & 17 & médio & & amarelo \\
\hline 164 & 17 & escasso & & amarelo \\
\hline 165 & 24 & " & & amarelo \\
\hline 166 & 17 & $"$ & & $\longrightarrow$ \\
\hline 167 & 24 . & médio & & amarelo \\
\hline 168 & 17 & $"$ & & \\
\hline 169 & 17 & escasso & & amarelo \\
\hline 170 & 17 & médio & & amarelo \\
\hline 171 & 18 & escasso & & amarelo \\
\hline 172 & $1 i$ & $"$ & & amarelo \\
\hline 173 & 17 & médio & & amarelo \\
\hline 174 & 17 & escasso & & amarelo \\
\hline 175 & 17 & $"$ & & $-\ldots$ \\
\hline 176 & 17 & $"$ & & amarelo claro \\
\hline 177 & 24 & $"$ & & amarelo \\
\hline 178 & 30 & $"$ & & amarelo \\
\hline 179 & 17 & $"$ & & amarelo \\
\hline 180 & 24 & $"$ & & amarelo \\
\hline 181 & 18 & médio & & amarelo \\
\hline 182 & 17 & $"$ & & amarelo \\
\hline 183 & 14 & escasso & & amarelo avermelliado \\
\hline 184 & 17 & $"$ & & amarelo \\
\hline 185 & 14 & $"$ & & amarelo \\
\hline 186 & 17 & $"$ & $\vdots$ & amarelo \\
\hline 188 & 14 & $"$ & : & amarelo claro \\
\hline 189 & 17 & médion & & - \\
\hline 190 & 17 & $"$ & & amarelo \\
\hline 191 & 9 & escasso & & amarelo claro \\
\hline 192 & 9 & " & & amarelo claro \\
\hline 193 & 9 & $"$ & ' & $\longrightarrow$ \\
\hline 194 & 9 & $"$ & & atnarelo claro \\
\hline 195 & 9 & $"$ & & amarelo \\
\hline 196 & 9 & $"$ & & amarelo \\
\hline 197 & 9 & $"$ & $\vdots$ & amarelo \\
\hline 198 & 9 & $"$ & & amarclo \\
\hline 199 & 9 & $"$ & $!$ & amarelo \\
\hline 200 & 9 & $"$ & $\vdots$ & amarelo \\
\hline 201 & 9 & $"$ & $\vdots$ & amarelo \\
\hline 202 & 9 & $"$ & : & amarelo \\
\hline 203 & 16 & médio & $\vdots$ & amarelo \\
\hline 204 & 9 & $"$ & ! & amarelo \\
\hline 205 & 9 & escasso & & amarelo \\
\hline 206 & 9 & $"$ & & $-\div$ \\
\hline 207 & 9 & $"$ & : & amarelo. \\
\hline 208 & 9 & $"$ & & amarelo \\
\hline 209 & 9 & $"$ & & $\longrightarrow$ \\
\hline 210 & 9 & $"$ & & - \\
\hline 211 & 16 & médio & & $\longrightarrow$ \\
\hline 212 & $\begin{array}{r}9 \\
16\end{array}$ & " & & - \\
\hline 213 & 10 & $n$ & & ams \\
\hline
\end{tabular}


Anais da E. S. A. «Luiz de Queiroz»

\begin{tabular}{|c|c|c|c|}
\hline $\begin{array}{c}\text { No da } \\
\text { cepa }\end{array}$ & $\begin{array}{l}\text { No de } \\
\text { dias }\end{array}$ & Desenvolvimento & Pigmento solúvel \\
\hline $\begin{array}{l}214 \\
215 \\
216 \\
217 \\
218 \\
219 \\
220 \\
221 \\
222 \\
223 \\
224 \\
225 \\
226 \\
227 \\
228 \\
229 \\
230 \\
231 \\
232 \\
233 \\
234 \\
235 \\
236 \\
237 \\
238 \\
239 \\
240 \\
241 \\
242 \\
243 \\
244 \\
245 \\
246 \\
247 \\
248 \\
249 \\
250 \\
251 \\
252 \\
253 \\
254 \\
255 \\
256 \\
257 \\
258 \\
259 \\
260 \\
261 \\
262 \\
263 \\
264 \\
265\end{array}$ & $\begin{array}{r}16 \\
9 \\
9 \\
9 \\
9 \\
9 \\
9 \\
16 \\
16 \\
9 \\
9 \\
21 \\
9 \\
9 \\
9 \\
16 \\
16 \\
16 \\
16 \\
9 \\
9 \\
16 \\
16 \\
16 \\
21 \\
16 \\
21 \\
9 \\
9 \\
9 \\
(-) \\
16 \\
16 \\
16 \\
16 \\
16 \\
21 \\
9 \\
9 \\
16 \\
16 \\
16 \\
9 \\
9 \\
9 \\
9 \\
16 \\
9 \\
9 \\
21 \\
21 \\
16\end{array}$ & 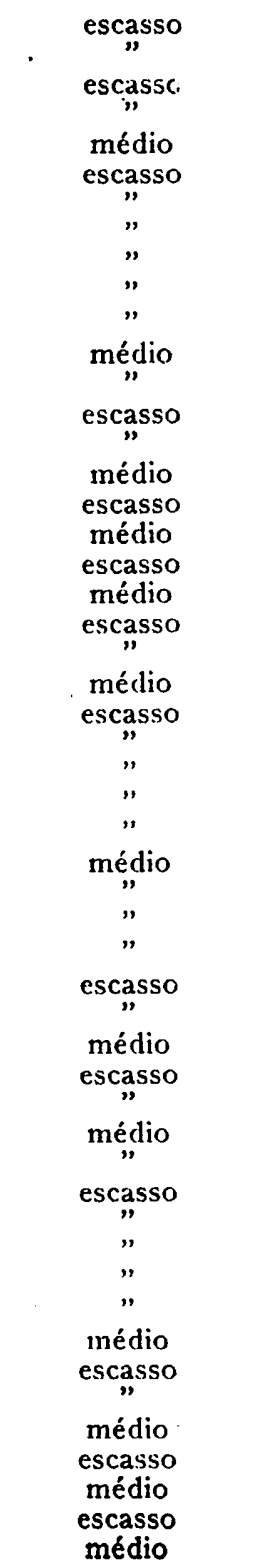 & 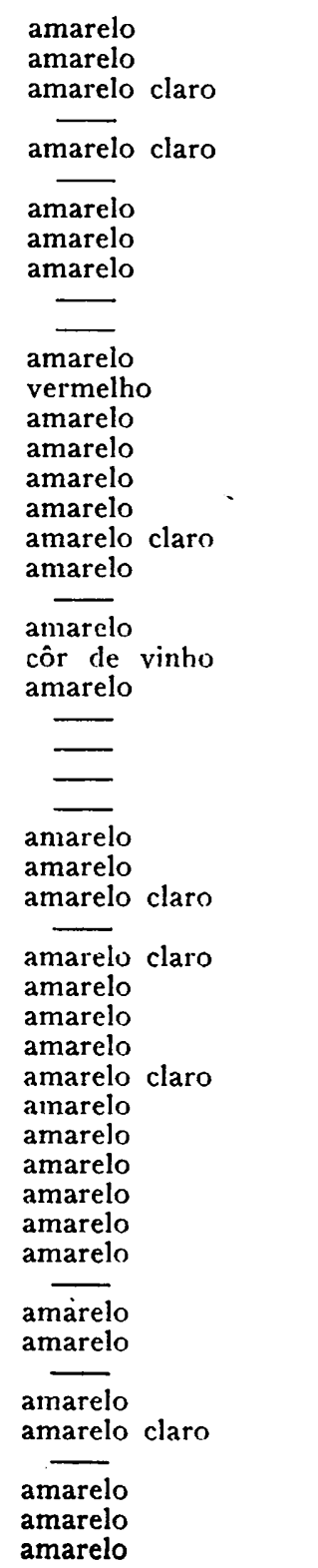 \\
\hline
\end{tabular}




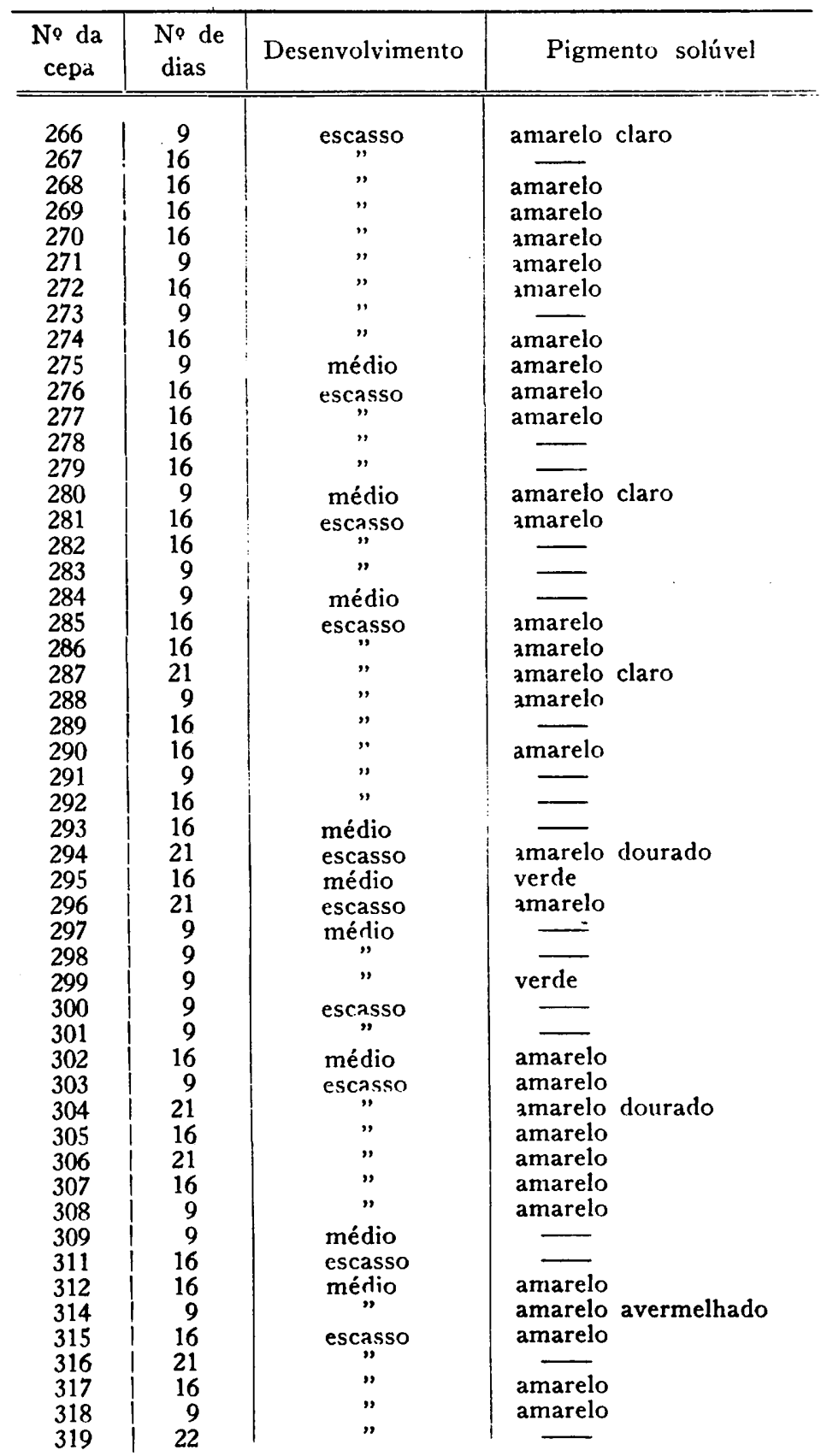




\begin{tabular}{|c|c|c|c|}
\hline $\begin{array}{c}\text { No da } \\
\text { cepa }\end{array}$ & $\begin{array}{l}\text { No de } \\
\text { dias }\end{array}$ & Desenvolvimento & Pigmento solúvel \\
\hline 320 & 30 & escasso & amarelo \\
\hline 321 & 15 & $"$ & $\longrightarrow$ \\
\hline 323 & 22 & $"$ & umarelo dourado \\
\hline 324 & 30 & $"$ & : $\overline{\text { amarelo }}$ \\
\hline $\begin{array}{l}325 \\
326\end{array}$ & $\begin{array}{l}(-) \\
(-)\end{array}$ & $"$ & $\begin{array}{l}\text { amareio } \\
\text { amarelo }\end{array}$ \\
\hline 327 & 22 & $"$ & amarclo \\
\hline 328 & 30 & $"$ & amarelo \\
\hline 329 & 30 & $"$ & anmarelo \\
\hline 330 & 22 & $"$ & vercle \\
\hline 331 & 15 & $"$ & . amarelo dourado \\
\hline 332 & 22 & $"$ & ए \\
\hline $\begin{array}{l}334 \\
335\end{array}$ & $\begin{array}{l}22 \\
22\end{array}$ & " & amarelo \\
\hline 336 & $(-)$ & $"$ & amarelo \\
\hline 337 & 15 & $"$ & castanho \\
\hline 338 & 30 & $"$ & verde \\
\hline 339 & 15 & $"$ & amarelo claro \\
\hline 340 & 15 & $"$ & ¿ inarelo claro \\
\hline
\end{tabular}




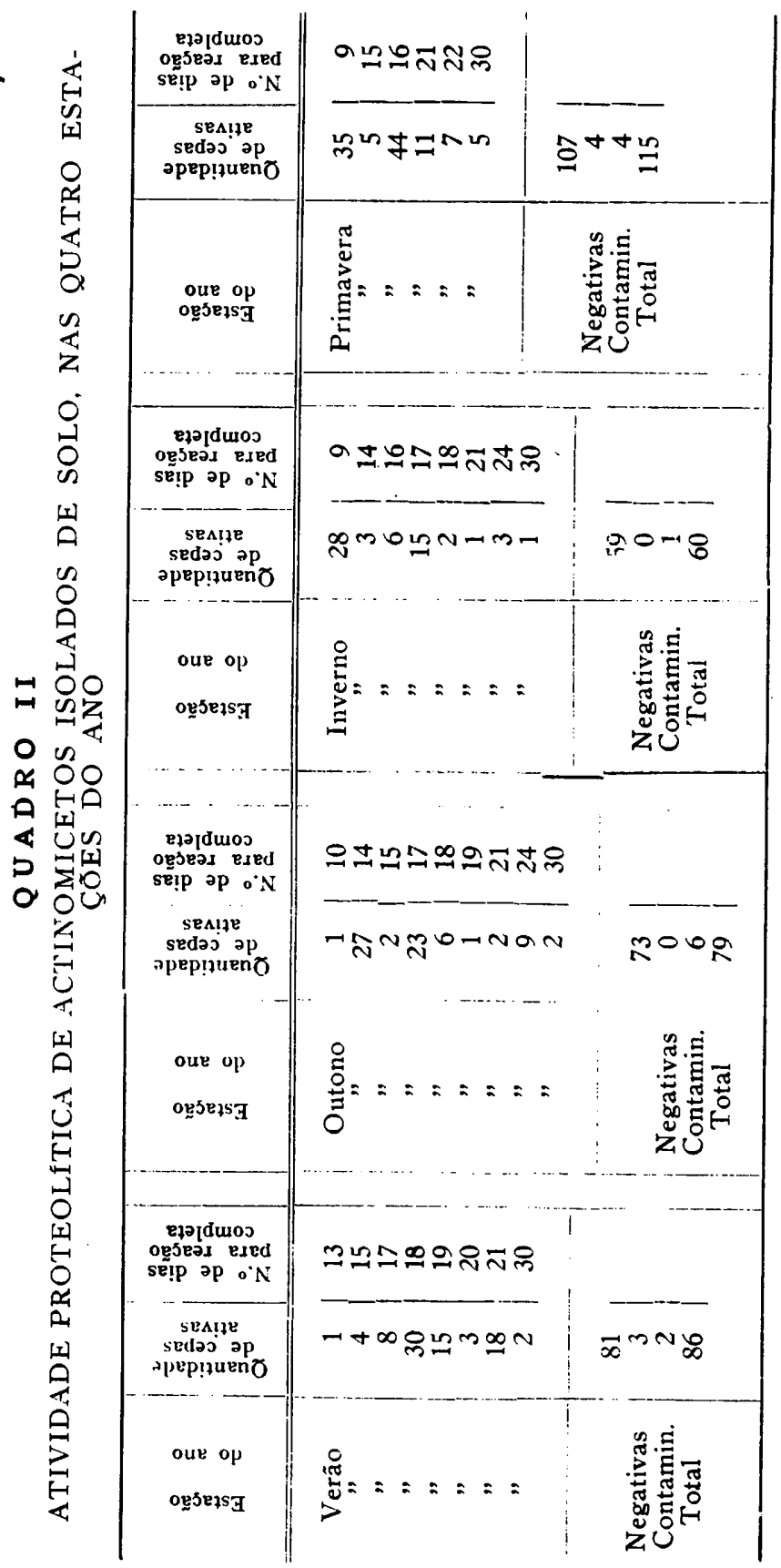




\section{Q U A D R O I I I}

QUANTIDADE DE CEPAS ATIVAS EM FUNÇÃO DO TEMPO

\begin{tabular}{|c|c|c|c|c|c|}
\hline \multirow{2}{*}{$\begin{array}{c}\text { N. } .^{\circ} \text { DE } \\
\text { DIAS - }\end{array}$} & \multicolumn{5}{|c|}{ QUANTIDADE DE CEPAS ATIVAS } \\
\hline & Verão & Inverno & Outono & $\begin{array}{c}\text { Prima- } \\
\text { vera }\end{array}$ & TOTAL \\
\hline $\begin{array}{c}9 \\
10 \\
13 \\
14 \\
15 \\
16 \\
17 \\
18 \\
19 \\
20 \\
21 \\
22 \\
24 \\
30 \\
\text { TOTAL }\end{array}$ & $\begin{array}{r}4 \\
8 \\
8 \\
30 \\
15 \\
3 \\
18 \\
\\
2 \\
81\end{array}$ & $\begin{array}{r}1 \\
27 \\
2 \\
23 \\
6 \\
1 \\
2 \\
9 \\
2 \\
73\end{array}$ & $\begin{array}{r}28 \\
3 \\
\\
6 \\
15 \\
2 \\
\\
1 \\
\\
3 \\
1 \\
59\end{array}$ & $\begin{array}{r}11 \\
7 \\
5 \\
5 \\
107\end{array}$ & $\begin{array}{r}63 \\
1 \\
1 \\
30 \\
11 \\
50 \\
46 \\
38 \\
16 \\
3 \\
32 \\
7 \\
12 \\
10 \\
320\end{array}$ \\
\hline
\end{tabular}

Q U A D R O I V

PORCENTAGEM DA ATIVIDADE PROTEOLITICA

\begin{tabular}{c|c|c|c|c|c}
\hline \multirow{2}{*}{$\begin{array}{c}\text { N.9 DE } \\
\text { DIAS }\end{array}$} & \multicolumn{3}{|c|}{ PORCENTAGEM DAS CEPAS ATIVAS } \\
\cline { 2 - 6 } & Verão & Outono & Inverno & $\begin{array}{r}\text { Prima- } \\
\text { vera }\end{array}$ & TOTAL \\
\hline 9 & 0,31 & 0,31 & 8,65 & 10,70 & 19,26 \\
10 & & 0,31 & & & 0,31 \\
13 & 0,31 & 8,25 & 0,91 & & 0,31 \\
14 & 1,22 & 0,61 & & 1,52 & 9,16 \\
15 & & & 1,83 & 13,45 & 15,35 \\
16 & 2,44 & 7,03 & & 4,58 & 14,05 \\
17 & 9,17 & 1,83 & 0,61 & & 11,61 \\
18 & 4,58 & 0,31 & & & 4,89 \\
19 & 0,91 & 0,61 & 0,31 & 3,36 & 0,91 \\
20 & 5,50 & 0,48 & 9,48 \\
21 & & 2,75 & 0,91 & 2,14 & 2,14 \\
22 & & 0,61 & 0,31 & 1,52 & 3,66 \\
24 & 0,61 & & & & 3,05 \\
30 & & & &
\end{tabular}


ATIVIDADE PROTEOLITICA DAS CEPAS DE VERÃO

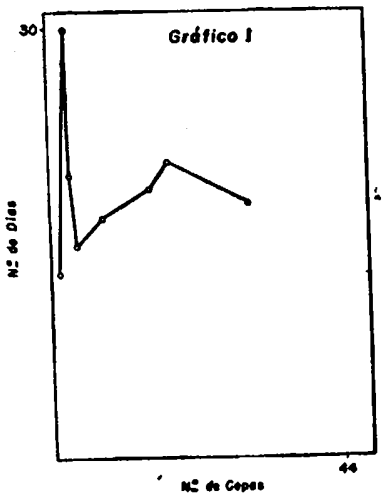

ATIVIDADE PAOTEOLITICA DAS CEPAS DE INVERNO

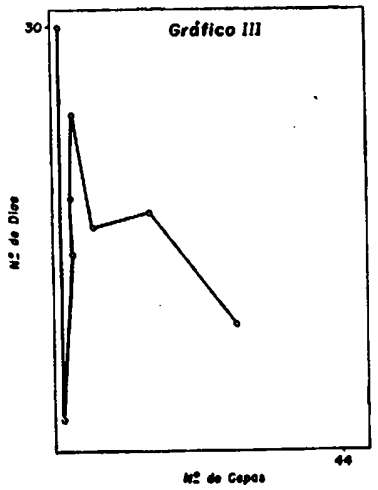

ATIVIDAdE PROTEOLÍTICA DA CEPAS OE OUTONO

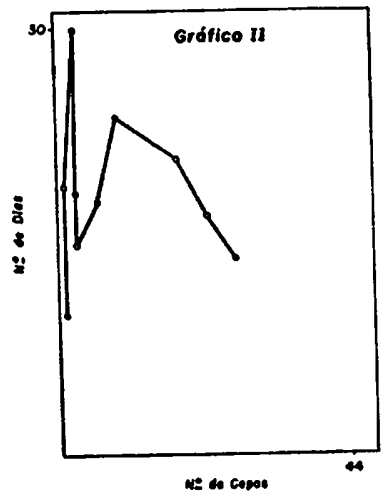

ATIVIDADE PROTEOLITICA DAS CEFAS DE PRIMAVERA

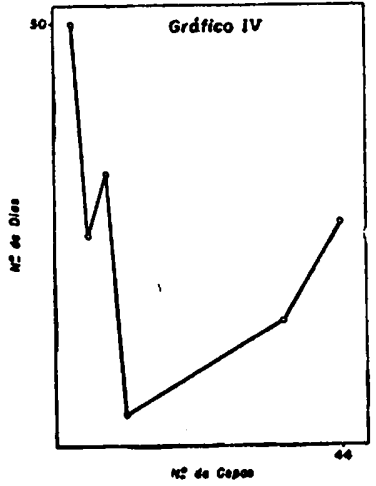




\section{4. - DISCUSSÃO DOS RESULTADOS}

$\mathrm{Na}$ primavera houve maior ocorrência de Actinomicetos representados por 115 cepas: segue-se o verão com 86 , depois o outono com 79 e, finalmente, o inverno com 60 cepas.

Os gráficos de I-IV ilustram a notável diferença entre a intensidade da atividade proteolítica das cepas nas 4 estações anuais.

Pelos quadros I e II observamos apenas 7 cepas inativas, representando sòmente $2,15 \%$ sôbre o total.

$\mathrm{O}$ quadro III nos demonstra que o maior número de cepas ativas realizou a cisão completa da gelatina em 9 dias apenas, seguindo-se outras que levaram 16 dias, 17, 18, 21 dias ou mais, revelando forte atividade proteolítica das cepas isoladas naquele lápso de tempo.

O quadro IV revela que a maior atividade proteolitica foi realizada em 16 dias, pelas cepas da primavera, seguindo-se aquelas com 9 dias, também da primavera.

A maioria das cepas foi isolada na primavera, época de clima mais ameno, com regular quantidade de chuva e temperatura média. A quantidade de matéria orgânica foi mantida aproximadamente a mesma durante o ano: não se pode, pois, atribuir a variação numérica das cepas à modificação quantitativa da matéria orgânica.

\section{5. - CONCLUSÖES}

Quase a totalidade dos Actinomicetos Isolados possui atividade proteolítica, representada por $97,85 \%$ sôbre o total.

As cepas isoladas na primavera gozam de predominância numérica sôbre os demais e são exatamente essas que possuem mais pronunciada atividade proteolítica.

Atribui-se ao clima dessa estação anual essa vantajosa diferença, porquanto o teor de matéria orgânica foi mantido aproximadamente num mesmo nivel.

Observamos enérgica capacidade proteolítica num limite máximo de 16 dias, nas cepas da primavera.

Sendo êsses Actinomicetos Isolados de solo podemos supor, com maior razão, que em seu habitat natural essa função seja igual senão mais intensa.

Disso concluimos que êsse solo de onde provieram estas cepas possui uma das principais caracteristicas de fertilidade.

Os Actinomicetos desempenham no solo um papel tão importante quanto os demais componentes da microflora terrícola. 


\section{6. - SUMMARY}

Among 327 strains of Actinomycetes isolated in 1958 during the four seasons, 97,85 per cent had proteolytic activity.

Most of the strains were isolated in spring time.

About the organic matter no conclusions were reached, because it was mantained constant with a average value of 4.099 . So the different number of the strains was a consequence of the season.

We can conclude that the Latosol red-yellow soil, from where these microorganisms were isolated, has a strong proteolytic capacity, since this reaction is very strong in a maximum limit of sixteen days during the spring season.

Consequently, this soil has one of the most importante caracteristics of fertility.

The role of the Actinomycetes in the soil is so important of the soil microflora.

\section{7. - LITERATURA CITADA}

1 - BALDACCI, E., G. F. Comaschi, T. Scotti and C. Spalla 1953 - General criteria for the systematics of genera and species of Actinomycetes (Streptomyces) and Micromonospora, Symposium Actinomycetales, morfologia, biologia e sistemática, VI Congresso Internazionale di Microbiologia, p. 36.

2 - WAKSMAN, S. A. 1916 - Bacteria, actinomyces and fungi in the soil, J. Bact., 1: 101.

3 - WAKSMAN, S. A., and R. E. Curtis 1918 - The occurrence of actinomycetes in the soil, Soil Sci., 6: 309-319.

4 - WAKSMAN, S. A. 1950 - The Actinomycetes, Annales Cryptogamici et Phytopathologici, vol. 9, Waltham, Mass. U. S. A., publ. by Chronica Botanica Co., p. 134. 
